Int. J. Electrochem. Sci., 16 (2021) Article ID: 21054

International Journal of

ELECTROCHEMICAL

SCIENCE

wWw.electrochemsci.org

\title{
A Novel Adaptive Particle Swarm Optimization Algorithm Based High Precision Parameter Identification and State Estimation of Lithium-Ion Battery
}

\author{
Mingfang He ${ }^{1}$, Shunli Wang ${ }^{1, *}$, Carlos Fernandez, ${ }^{2}$ Chunmei $\mathrm{Yu}^{1}$, Xiaoxia $\mathrm{Li}^{1}$, \\ Etse Dablu Bobobee ${ }^{1}$ \\ ${ }^{1}$ School of Information Engineering, Southwest University of Science and Technology, Mianyang \\ 621010, China; \\ ${ }^{2}$ School of Pharmacy and Life Sciences, Robert Gordon University, Aberdeen AB10-7GJ, UK. \\ *E-mail: $\underline{497420789 @ \text { qq.com }}$
}

doi: $10.20964 / 2021.05 .55$

Received: 18 November 2020 / Accepted: 12 January 2021 / Published: 31 March 2021

Lithium-ion batteries are widely used in new energy vehicles, energy storage systems, aerospace and other fields because of their high energy density, long cycle life and high-cost performance. Accurate equivalent modeling, adaptive internal state characterization and accurate state of charge estimation are the cornerstones of expanding the application market of lithium-ion batteries. According to the highly nonlinear operating characteristics of lithium-ion batteries, the Thevenin equivalent model is used to characterize the operating characteristics of lithium-ion batteries, particle swarm optimization algorithm is used to process the measured data, and adaptive optimization strategy is added to improve the global search ability of particles, and the parameters of the model are identified innovatively. Combined with extended Kalman algorithm and Sage-Husa filtering algorithm, the state-of-charge estimation model of lithium ion battery is constructed. aiming at the influence of fixed and inaccurate noise initial value in traditional Kalman filtering algorithm on SOC estimation results, Sage-Husa algorithm is used to adaptively correct system noise. The experimental results under HPPC condition show that the maximum error of the model is less than $1.5 \%$. Simulation results of SOC estimation algorithm under two different operating conditions show that the maximum estimation error of adaptive extended Kalman algorithm is less than 0.05 , which realizes high-precision lithium battery model parameter identification and highprecision state-of-charge estimation.

Keywords: Lithium-ion battery, Adaptive particle swarm optimization, Sage-Husa algorithm, Adaptive extended Kalman filter, State of charge estimation

$\underline{\text { FULL TEXT }}$ 
(C) 2021 The Authors. Published by ESG (www.electrochemsci.org). This article is an open access article distributed under the terms and conditions of the Creative Commons Attribution license (http://creativecommons.org/licenses/by/4.0/). 